\title{
Melatonin Synergizes with Sorafenib to Suppress Pancreatic Cancer via Melatonin Receptor and PDGFR- $\beta$ /STAT3 Pathway
}

\author{
Zhenghuan Fang Kyung Hee Jung Hong Hua Yan Soo-Jung Kim \\ Marufa Rumman Jung Hee Park Boreum Han Ji Eun Lee Yeo wool Kang \\ Joo Han Lim Soon-Sun Hong
}

Department of Biomedical Sciences \& Medicine, College of Medicine, Inha University, 3-ga, Sinheung-

dong, Jung-gu, Incheon, Republic of Korea

\section{Key Words}

Sorafenib • Melatonin • Pancreatic cancer • Apoptosis • PDGFR- $\beta /$ STAT3

\begin{abstract}
Background/Aims: Pancreatic ductal adenocarcinoma (PDAC) is one of the most lethal malignant tumors with poor prognosis. Conventional chemotherapies including gemcitabine have failed owing to weak response and side effects. Hence novel treatment regimens are urgently needed to improve the therapeutic efficacy. In this study, we aimed to assess the anticancer activity of melatonin and sorafenib as a novel therapy against PDAC. Methods: We used various apoptosis assay and PDAC xenograft model to assess anticancer effect in vitro and in vivo. We applied phospho-receptor tyrosine kinase (RTK) array and phospho-tyrosine kinase array to explore the mechanism of the combined therapy. Western blotting, proximity ligation assay, and immunoprecipitation assay were also performed for validation. Results: Melatonin synergized with sorafenib to suppress the growth of PDAC both in vitro and in vivo. The effect was due to increased apoptosis rate of PDAC cells that was accompanied by mitochondria dysfunction. The enhanced anticancer efficacy by the co-treatment could be explained by blockade of PDGFR- $\beta$ /STAT3 signaling pathway and melatonin receptor (MT)mediated STAT3. Conclusions: Melatonin reinforces the anticancer activity of sorafenib by downregulation of PDGFR- $\beta$ /STAT3 signaling pathway and melatonin receptor (MT)-mediated STAT3. The combination of the two agents might be a potential therapeutic strategy for treating PDAC.
\end{abstract}

\section{Introduction}

Pancreatic ductal adenocarcinoma (PDAC), the fourth-most frequent cause of human cancer-related deaths, is extremely aggressive with a high risk of metastasis, recurrence,

Zhenghuan Fang and Kyung Hee Jung contributed equally to this work.

Soon Sun Hong, Ph.D.

KARGER
Department of Biomedical Sciences, College of Medicine, Inha University

3-ga, Sinheung-dong, Jung-gu, Incheon 400-712, (Republic of Korea)

Tel. +82-32-890-3683, Fax +82-32-890-2462, E-Mail hongs@inha.ac.kr 


\section{Cellular Physiology Cell Physiol Biochem 2018;47:1751-1768 \\ \begin{tabular}{l|l} 
DOI: 10.1159/000491058 & a 2018 The Author(s). Published by S. Karger AG, Basel \\
www.karger.com/cpb
\end{tabular}}

Fang et al.: Synergistic Effect of Sorafenib and Melatonin

and the overall poorest prognosis [1, 2]. Although surgical resection is currently the main therapeutic strategy for PDAC, consequent outcomes are not outstanding [3]. Moreover, conventional chemotherapies including gemcitabine and its combinations with other therapeutic agents have often failed owing to weak responsiveness and the incidence of side effects [4]. These observations have led us to develop a more effective and safer therapeutic approach toward this malignant tumor.

The multi-kinase inhibitor sorafenib (Bay 43-9006, Nexavar) inhibits various signaling pathways including RAF/MEK/ERK cascades, resulting in the suppression of cell proliferation and survival [5]. It also exhibits anti-angiogenic effect through inhibition of various target receptors including VEGFR and PDGFR- $\beta$ [5]. In addition, it inhibits DNA synthesis and induces tumor cell death in various human cancers [6]. Sorafenib alone and its combination with other drugs has shown potent anti-proliferative and pro-apoptotic efficacy in PDAC cells $[7,8]$. Notably, it increases apoptotic cell death through the mitochondrial-dependent intrinsic pathway, which is associated with cytochrome $c$ release from the mitochondria into the cytoplasm [9]. Despite these promising preclinical findings, sorafenib have shown modest results or incomplete therapeutic outcomes in clinical trials due to limited efficacy and drug resistance, as well as countless side effects $[10,11]$. Hence, new chemotherapeutic strategies are needed to increase the efficacy of sorafenib and reduce its toxicity. Numerous evidences support combination therapies in cancer, using anticancer chemicals or various supplements $[12,13]$. Supplements such as vitamins (C, E, and K) and hormones (estrogen and insulin) have exhibited beneficial anticancer effects when used as a single agent or in combination with conventional anticancer drugs $[8,13]$. For example, sorafenib combined with hymecromone, a dietary supplement, was shown to be highly effective in controlling renal cell carcinoma [14].

Melatonin (N-acetyl-5-methoxytryptamine), a commonly taken supplement used as a sleep aid, is a controller of the human circadian rhythm [15]. As a major product of the pineal gland, melatonin is known to regulate immunological function, exert antioxidant properties, and protect against organ injury $[16,17]$. It has also been proposed to act as an oncostatic agent against several types of cancer $[18,19]$. In addition, combinations of melatonin with various potent anticancer agents, such as cisplatin, 5-fluorouracil (5-FU), and doxorubicin, exhibited strong anticancer effects from in vitro and in vivo studies [20-22]. Accordingly, melatonin is considered as a potential candidate to enhance the anticancer activity of chemotherapeutic agents. In PDAC, melatonin is known to stimulate pro-apoptotic activity through regulation of Bcl-2 family proteins, caspase- 3 and caspase-9 in vitro [23]. Moreover, melatonin promoted apoptosis by inducing the intrinsic mitochondrial pathway in rat PDAC cells [24]. Although accumulating evidences support the anti-cancer effect of melatonin, the specific molecular mechanism by which melatonin inhibits tumor is unclear, and uncertainty regarding combinational treatment of melatonin and anticancer drugs remains.

Recently, combined treatment of sorafenib and melatonin was reported to exert synergistic anticancer activity via the JNK/c-Jun pathway in hepatocellular carcinoma [25]. However, these agents have never been tested to treat PDAC. Given the enhancing effect of melatonin on sorafenib efficacy in other cancer types, we sought to determine whether these two agents act synergistically against PDAC and investigated the underlying mechanism of action.

\section{Materials and Methods}

\section{Cells and reagents}

MIAPaCa-2 and PANC-1 human PDAC cells (American Type Culture Collection, Manassas, VA, USA) were cultured in Dulbecco's modified Eagle's medium (DMEM) supplemented with $10 \%$ fetal bovine serum (FBS), and $1 \%$ penicillin/streptomycin at $37^{\circ} \mathrm{C}$ in a humidified atmosphere composed of $95 \%$ air and $5 \% \mathrm{CO}_{2}$. Sorafenib (LC Laboratories, Woburn, MA, USA) was dissolved in dimethyl sulfoxide (DMSO) at a concentration of $10 \mathrm{mM}$ before use. Melatonin (Sigma-Aldrich, St. Louis, MO, USA) was dissolved in DMSO at a concentration of $2 \mathrm{M}$ before use (final DMSO concentration, $<0.1 \%$ ). 


\section{Cellular Physiology Cell Physiol Biochem 2018;47:1751-1768

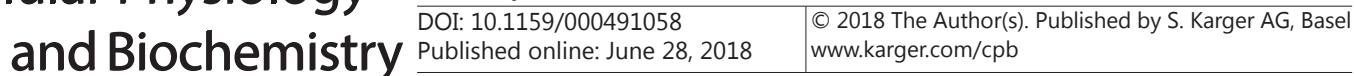

Fang et al.: Synergistic Effect of Sorafenib and Melatonin

\section{Measurement of cell proliferation}

Cell viability was assessed using a 3-(4, 5-dimethylthiazol-2-yl)-2, 5-diphenyl tetrazolium bromide (MTT) assay. Cells were plated at a density of $6 \times 10^{3}$ cells per well in 96-well plates and incubated for $24 \mathrm{~h}$. The medium was then removed, and cells were treated with different concentrations of sorafenib (1-10 $\mu \mathrm{M})$ alone or with melatonin $(0.1,1$, or $2 \mathrm{mM})$ for $48 \mathrm{~h}$. Next, $20 \mu \mathrm{l}$ of an MTT solution $(2 \mathrm{mg} / \mathrm{mL})$ was added to each well, and the plate was incubated at $37^{\circ} \mathrm{C}$ for an additional $4 \mathrm{~h}$. The formazan crystals that formed in the cells were dissolved in DMSO (200 $\mu$ l per well) with constant shaking for $30 \mathrm{~min}$. Absorbance of the solution was then measured with a microplate reader at $540 \mathrm{~nm}$. This assay was conducted in triplicate, and a combination index for sorafenib and melatonin was calculated using CompuSyn v1.0 (Biosoft, Cambridge, USA) according to the method of Chou and Talalay, where $\mathrm{CI}<1, \mathrm{CI}=1$, and $\mathrm{CI}>1$ indicate synergistic, additive and antagonistic effects, respectively [26].

TUNEL assay

After incubating for $24 \mathrm{~h}$ with sorafenib $(10 \mu \mathrm{M})$ and/or melatonin $(2 \mathrm{mM})$, cells were fixed with an acetic acid:ethanol (1:2) solution for $5 \mathrm{~min}$ at $-20^{\circ} \mathrm{C}$, DNA fragmentation was detected using a terminal deoxynucleotidyl transferase-mediated nick-end labeling (TUNEL) assay, as described by the manufacturer of the ApopTag Peroxidase In Situ Apoptosis Detection (Kit\#S7100; Merck Millipore, Temecula, CA, USA).

\section{Annexin-V assay}

MIAPaCa-2 cells were plated on 18-mm glass coverslips and grown to approximately $70 \%$ confluence. The cells were treated with sorafenib and melatonin, alone and in combination for $24 \mathrm{~h}$, then permeabilized, blocked and incubated with anti-Annexin V primary antibody (Abcam, Cambridge, USA) at $4^{\circ} \mathrm{C}$ overnight. The cells were incubated with fluorescence-conjugated anti-mouse secondary antibody for $1 \mathrm{~h}$ and then stained with DAPI (4',6-diamidino-2-phenylindole) solution (NucBlue; Sigma-Aldrich, St. Louis, MO, USA) for $30 \mathrm{~min}$ in the dark at room temperature. The cells were mounted with DABCO (Sigma-Aldrich, St. Louis, MO, USA) and viewed under a confocal laser-scanning microscope (Fluo View 1000; Olympus, Tokyo, Japan).

\section{Western blotting}

Total cellular proteins were extracted with sterile RIPA lysis buffer (Biosesang, Korea) consisting of $150 \mathrm{mM} \mathrm{NaCl}, 1 \%$ Triton X-100, 1\% sodium deoxycholate, 0.1\% SDS, $50 \mathrm{mM}$ Tris-HCl pH 7.5, and $2 \mathrm{mM}$ EDTA supplemented with Xpert Protease \& Phosphatase Inhibitor Cocktail (GenDEPOT, Barker, TX, USA) solution (100X) prior to use. The proteins were separated by sodium dodecyl sulfate-polyacrylamide gel electrophoresis (SDS-PAGE) and transferred onto nitrocellulose membranes. Membranes were incubated first with diluted primary antibodies overnight with gentle shaking at $4^{\circ} \mathrm{C}$, and then with horseradish peroxidase (HRP)-conjugated secondary antibodies. Thereafter, membranes were washed three times in PBS containing 0.1\% Tween-20 (PBST), and antigen-antibody complexes were visualized using enhanced chemiluminescence reagents (Clarity Western ECL Substrate; Bio-Rad, Hercules, CA, USA). Antibodies against Survivin, Bcl-2, PARP, phosphorylated CRAF (p-CRAF), p-MEK, MEK, p-ERK, ERK, p-PDGFR- $\beta$, p-STAT3, STAT3 were purchased from Cell Signaling Technology (Danvers, MA, USA), and XIAP, CRAF, SOD-2, PDGFR- $\beta$ from Santa Cruz Biotechnology (Dallas, TX, USA), VDAC-1 from Abcam (Cambridge, USA), p-DAPK1 from GeneTex (Irvine, CA, USA ), and $\beta$-actin from Sigma-Aldrich (St. Louis, MO, USA). Secondary goat antirabbit, goat anti-mouse, and donkey anti-goat antibodies were purchased from Santa Cruz Biotechnology.

\section{Cytochrome c localization}

MIAPaCa-2 cells were plated on 18-mm glass coverslips and grown to approximately $70 \%$ confluence. The cells were treated with sorafenib and melatonin, alone and in combination for $12 \mathrm{~h}$, then permeabilized, and incubated with $500 \mathrm{nM}$ MitoTracker Red probe (Molecular Probes Inc., Eugene, OR, USA) for 30 min at $37^{\circ} \mathrm{C}$. Next, the cells were washed twice with PBS, fixed in an acetic acid:ethanol (1:2) solution for 10 min at $-20^{\circ} \mathrm{C}$, and then incubated overnight at $4^{\circ} \mathrm{C}$ with an anti-cytochrome $c$ antibody (1:50; Santa Cruz Biotechnologies, Dallas, TX, USA). On the following day, the cells were washed twice with PBS and incubated with fluorescence-labeled anti-mouse secondary antibody (1:100; Dianova, Hamburg, Germany) for $1 \mathrm{~h}$ at room temperature. The cells were also stained with DAPI to visualize nuclei. The slides were then washed twice with PBS, mounted with DABCO (Sigma-Aldrich, St. Louis, MO, USA), and viewed under a confocal laser-scanning microscope (Fluo View 1000; Olympus). 


\section{Cellular Physiology Cell Physiol Biochem 2018;47:1751-1768

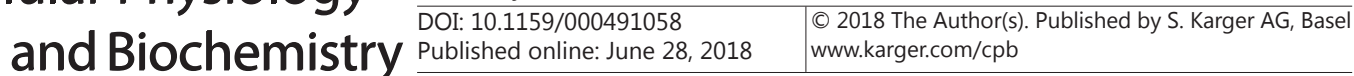

Fang et al.: Synergistic Effect of Sorafenib and Melatonin

\section{Measurement of mitochondrial membrane potential by JC-1 staining}

MIAPaCa-2 cells were plated on 18-mm glass coverslips and grown to approximately $70 \%$ confluence. The cells were then treated with sorafenib and melatonin, alone and in combination for $16 \mathrm{~h}$, followed by incubation with JC-1 solution (Cayman Chemical, Ann Arbor, MI, USA) for 20 min at $37^{\circ} \mathrm{C}$ in the dark. After staining with DAPI to visualize nuclei, slides were washed twice with PBS, mounted with DABCO (SigmaAldrich, St. Louis, MO, USA), and viewed by confocal laser-scanning microscopy (Fluo View 1000; Olympus).

\section{Measurement of caspase-3 activity}

MIAPaCa-2 cells were plated on 18-mm glass coverslips, grown to approximately $70 \%$ confluence, and treated with sorafenib and melatonin, alone and in combination for $24 \mathrm{~h}$. Cells were then permeabilized with $0.5 \%$ Triton X-100, blocked with $0.25 \%$ goat and $0.25 \%$ horse serum for $1 \mathrm{~h}$, and incubated first with an anti-cleaved caspase-3 antibody (1:20; Cell Signaling Technology, Danvers, MA, USA) overnight and then with tetramethyl rhodamine isothiocyanate (TRITC)-conjugated anti-rabbit secondary antibody (1:50; Dianova, Hamburg, Germany) for $1 \mathrm{~h}$. Slides were stained by DAPI to visualize nuclei, washed twice with PBS, and mounted with DABCO (Sigma-Aldrich, St. Louis, MO, USA) for confocal laser-scanning microscopy (Fluo View 1000; Olympus).

\section{Cell cycle analysis}

MIAPaCa- 2 cells $\left(5 \times 10^{5}\right)$ were plated in $100-\mathrm{mm}$ culture dishes at $\sim 70 \%$ confluence and incubated at $37^{\circ} \mathrm{C}$ for $24 \mathrm{~h}$. The next day, cells were treated with sorafenib and melatonin, alone and in combination. Floating and adherent cells were collected and fixed overnight in a cold $70 \%$ ethanol at $4^{\circ} \mathrm{C}$. After washing with PBS, the cells were stained with $50 \mu \mathrm{g} / \mathrm{mL}$ propidium iodide and $100 \mu \mathrm{g} / \mathrm{mL}$ RNase A for $30 \mathrm{~min}$ in the dark at $37^{\circ} \mathrm{C}$, and then analyzed by fluorescence-activated cell sorting (FACS) using a FACS Calibur ${ }^{\mathrm{TM}}$ flow cytometer (Becton Dickinson, San Jose, CA, USA) to determine the percentage of cells in the sub- $G_{1}$ (apoptotic) phase of the cell cycle. All experiments were performed in triplicate.

\section{Isolation of mitochondria}

Detached cells were washed with cold DPBS, resuspended in hypotonic buffer ( $5 \mathrm{mM}$ Tris, $5 \mathrm{mM}$ $\mathrm{KCl}, 1.5 \mathrm{mM} \mathrm{MgCl}_{2}, 0.1 \mathrm{mM}$ EGTA, and $1 \mathrm{mM} \mathrm{DTT}$ ), and homogenized using a glass-Teflon tissue grinder (40-50 strokes). A nuclear fraction (pellet) and a post-nuclear fraction (supernatant) were prepared by centrifugation at $600 \times \mathrm{g}$ for $10 \mathrm{~min}$ at $4^{\circ} \mathrm{C}$. A mitochondrial fraction (pellet) and cytosolic fraction (supernatant) were obtained by centrifugation of the post-nuclear fraction at $7000 \times \mathrm{g}$ for $10 \mathrm{~min}$ at $4^{\circ} \mathrm{C}$. For purification of mitochondria, the pellet was resuspended in a hypotonic buffer and centrifuged for $10 \mathrm{~min}$ at $7000 \times \mathrm{g}$. This washing step was repeated two times. Finally, the mitochondrial pellet was resuspended in RIPA buffer.

\section{Co-immunoprecipitation}

Cell lysates were prepared by washing cells twice in cold 1× PBS and incubating in NP-40 lysis buffer (50 mM Tris $\mathrm{HCl} \mathrm{pH} \mathrm{8.0,} 150 \mathrm{mM} \mathrm{NaCl}, 1 \%$ NP-40, 1x protease inhibitor cocktail (GenDEPOT, Barker, TX, USA) for $30 \mathrm{~min}$ at $4^{\circ} \mathrm{C}$ with gentle rocking. Lysates were cleared by microcentrifugation at 13, 000 r.p.m for $30 \mathrm{~min}$ at $4^{\circ} \mathrm{C}$. For co-immunoprecipitation, equal amounts of cell lysates were incubated with primary antibodies overnight on an end-over-end tube rotator at $4^{\circ} \mathrm{C}$. Pre-washed protein $\mathrm{G}$ agarose beads (Santa Cruz Biotechnology) were then added, and tubes were gently rocked at $4^{\circ} \mathrm{C}$ for an additional $6 \mathrm{~h}$. Complexes were washed twice with cold lysis buffer and examined by immunoblot analysis.

\section{Proximity ligation assay}

Heterodimerization of the serine/threonine kinases BRAF and CRAF was measured using an in situ proximity ligation assay (PLA). In this assay, a pair of oligonucleotide-labeled secondary antibodies (PLA probes) generates a signal only when the two antibodies are bound in close proximity, allowing the detection of protein-protein interaction in situ. MIAPaCa-2 cells were plated on 18-mm glass coverslips and allowed to adhere overnight at $37^{\circ} \mathrm{C}$. Cells were treated with sorafenib and melatonin, alone and in combination for $6 \mathrm{~h}$, then fixed with an acetic acid:ethanol (1:2) solution for $5 \mathrm{~min}$ at $-20^{\circ} \mathrm{C}$, and then BRAFCRAF heterodimerization was visualized by PLA using anti-CRAF and anti-BRAF antibodies. 


\section{Cellular Physiology Cell Physiol Biochem 2018;47:1751-1768 \\ \begin{tabular}{l|l} 
and Biochemistry Published online: June 28, 2018 & $\begin{array}{l}\text { (c) } 2018 \text { The Author(s). Published by S. Karger AG, Basel } \\
\text { www.karger.com/cpb }\end{array}$ \\
\hline
\end{tabular}}

Fang et al.: Synergistic Effect of Sorafenib and Melatonin

\section{Human Phospho-RTK array}

The relative levels of tyrosine phosphorylation of 49 distinct receptor tyrosine kinases (RTKs) were determined using a Human Phospho-RTK Assay kit (R\&D Systems, Minneapolis, MN, USA). MIAPaCa-2 cells were treated with sorafenib and melatonin, alone and in combination for $6 \mathrm{~h}$, and protein lysates were prepared as described above. After blocking for $1 \mathrm{~h}$ using Array Buffer 1, the arrays were incubated with 800 $\mu \mathrm{g}$ of protein lysates overnight at $4{ }^{\circ} \mathrm{C}$, then washed and incubated with an HRP-conjugated anti-phosphotyrosine detection antibody (1:5000). The membranes were developed using a Chemi Reagent Mix provided by the manufacturer, and the expression levels were densitometrically quantified using ImageJ software.

\section{Phospho-Kinase array}

Relative phosphorylation levels of 43 distinct kinases were determined using a Human PhosphoKinase Array kit (R\&D Systems). MIAPaCa-2 cells were treated with sorafenib and melatonin, alone and in combination for $6 \mathrm{~h}$, and then lysed as described above. After blocking for $1 \mathrm{~h}$ using Array Buffer 1, membranes were incubated with $500 \mu \mathrm{g}$ of protein lysates overnight at $4^{\circ} \mathrm{C}$, then washed and incubated with a streptavidin-HRP detection antibody (1:5000). Membranes were developed using ECL Western blotting detection reagents (Chemi reagent $\mathrm{A}$ and Chemi reagent $\mathrm{B}$ ) provided by the manufacturer, and the expression levels were densitometrically quantified using ImageJ software.

\section{Mouse xenograft models}

Xenograft models were prepared by inoculating $5 \times 10^{6}$ MIAPaCa- 2 cells suspended in PBS $(200 \mu \mathrm{L}$ per mouse) in the flank of 6-wk-old male BALB/c nude mice (Orient Bio, Korea). After tumors reached approximately $100 \mathrm{~mm}^{3}$ in size, mice were randomly divided into four groups: group 1, vehicle (control); group 2, sorafenib only (10 mg/kg); group 3, melatonin only ( $40 \mathrm{mg} / \mathrm{kg}$ ); group 4, combined sorafenib and melatonin, and were intraperitoneally administered once daily for 27 days. Tumor size was measured every 2 days, and tumor volume was calculated using the formula, $0.5 \times$ length $\times$ width $^{2}$. All animal experiments were performed in accordance with the guidelines of the Institutional Animal Care and Use Committee of Inha University Medical School (INHA IACUC).

\section{Immunohistochemistry}

Paraffin-embedded sections of tumors were blocked with normal goat or horse serum (Vector Laboratories, Burlingame, CA, USA) for $1 \mathrm{~h}$, and incubated at $4^{\circ} \mathrm{C}$ overnight in 1:50 dilutions of primary antibodies against cleaved caspase-3 and p-STAT3 (Cell Signaling Technology); proliferating cell nuclear antigen (PCNA; Abcam); and p-PDGFR- $\beta$ (Santa Cruz Biotechnology). Sections were then incubated with biotinylated secondary antibodies (1:100) for $1 \mathrm{~h}$. Immunoreactive proteins were visualized by first applying an avidin-biotin peroxidase complex solution (ABC kit; Vector Laboratories, Burlingame, CA, USA), then washing in PBS and developing with a diaminobenzidine tetrahydrochloride (DAB) substrate for 15 min with subsequent hematoxylin counterstaining. At least three random fields in each section were examined at a magnification of $200 \times$.

\section{Statistical analysis}

Data are expressed as means \pm standard deviation (S.D.). The significant differences among and between means was evaluated using analysis of variance (ANOVA) or unpaired Student's $t$-test, as appropriate. $P$-values $<0.05$ were considered statistically significant. Statistical analyses were performed using SPSS software for the MS Windows operating system (version 10.0; SPSS, Chicago, IL, USA).

\section{Results}

Combination of sorafenib and melatonin synergistically inhibited cell proliferation in PDAC cell lines

We evaluated anticancer activity of sorafenib and melatonin in human PDAC cells using a cell viability assay. Cells were treated with different concentrations of sorafenib $(1,5,10$ $\mu \mathrm{M})$, melatonin $(0.1,1$, or $2 \mathrm{mM})$, or both for $48 \mathrm{~h}$. Compared to treatment with either agent alone, co-treatment with both agents caused greater inhibition of cell growth (Fig. 1A). To 
identify synergistic effects of sorafenib and melatonin, we calculated combination index (CI) values using CompuSyn v1.0 (Biosoft). As shown in Fig. 1B, sorafenib and melatonin produced significant synergistic effects, with CI values $<1$ for the combination of $10 \mathrm{mM}$ sorafenib and $2 \mathrm{mM}$ melatonin in MIAPaCa-2 (CI = 0.053) and PANC-1 (CI $=0.828)$ cells.

\section{Combination of sorafenib with melatonin synergistically induced apoptosis}

Next, we examined whether the combination of sorafenib $(10 \mu \mathrm{M})$ and melatonin $(2 \mathrm{mM})$ induced apoptosis in MIAPaCa-2 cells. The combined treatment induced large numbers of TUNEL-positive cells compared with single treatment with either agent, which produced few apoptotic cells (Fig. 2A). Annexin-V staining assay, performed in parallel with TUNEL assays to measure DNA damage, showed that the combined treatment induced a higher level of apoptosis than either agent alone (Fig. 2B). And cell cycle analyses showed that the combined treatment also produced a significant increase in the sub-G1, apoptotic population ( 2.8-fold) compared with either agent alone group (Fig. 2C).

\section{Combination of sorafenib and melatonin increased mitochondrial-mediated apoptosis \\ Based on the apoptosis-} inducing effects of combination treatment, we next assessed whether the combined treatment altered the mitochondrial membrane potential in MIAPaCa-2 cells, using the membrane potentialsensitive fluorescent dye JC-1. In control cells, JC-1 accumulated in mitochondria as aggregates that emitted a red fluorescence in live cells, whereas the monomeric form which emitted a green fluorescence was prevalent in the cytoplasm of dead cells (Fig. 3A). As shown in Fig. 3A, combined treatment induced marked changes in mitochondrial membrane potential, as evidenced by a clear decrease in red fluorescence or increase in green fluorescence in most cells. Because changes in mitochondrial membrane

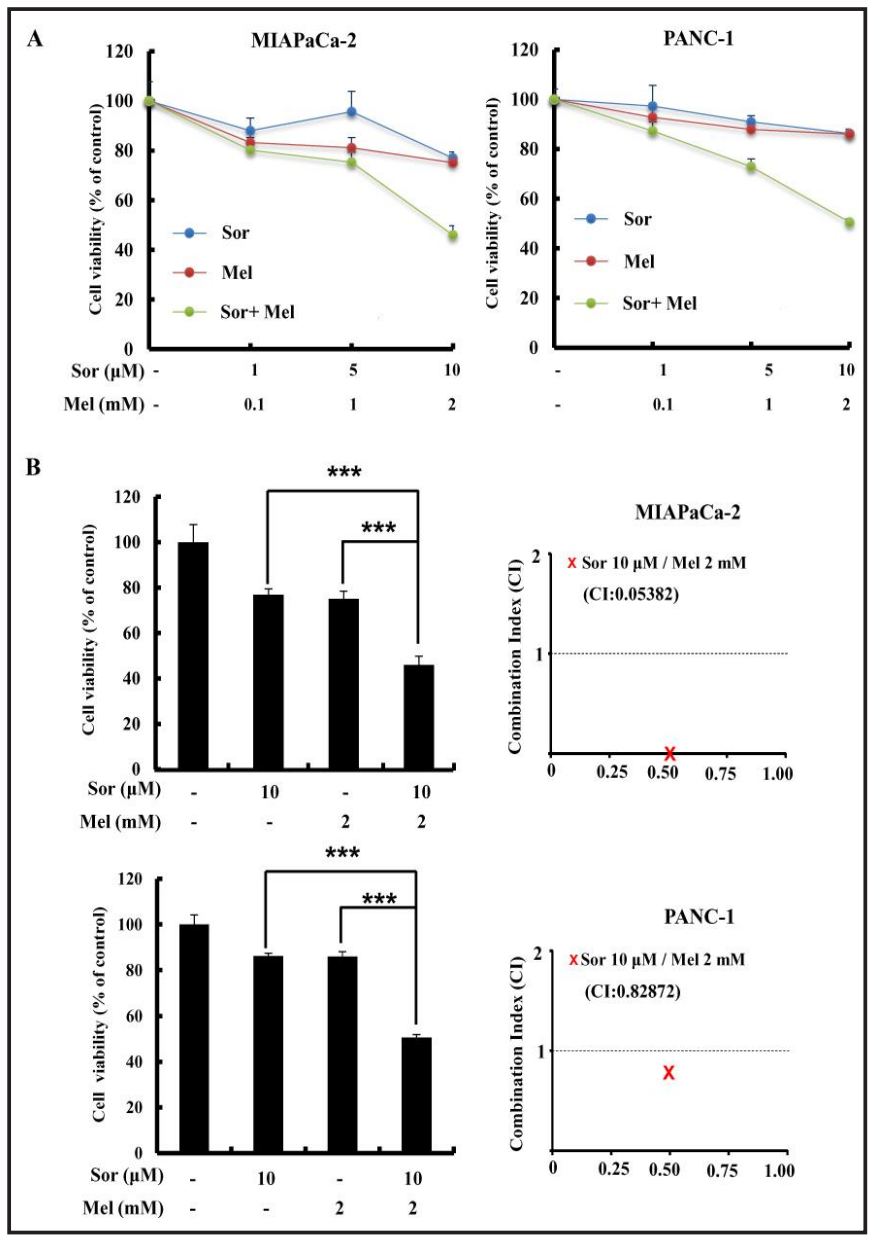

Fig. 1. Synergistic cytotoxic effects of sorafenib (Sor) and melatonin (Mel) on human PDAC cells. (A) MIAPaCa- 2 and PANC-1 cells were treated with Sor $(1,5$, or $10 \mu \mathrm{M})$ and/or Mel $(0.1,1$, or 2 $\mathrm{mM}$ ) for $48 \mathrm{~h}$, and cytotoxicity was determined using MTT assays. (B) Effects of combination treatment with Sor $(10 \mu \mathrm{M})$ and Mel (2 $\mathrm{mM}$ ) on the viability of MIAPaCa-2 (top left) and PANC-1 (bottom left) cells. CI values for Sor and Mel in MIAPaCa-2 and PANC-1 cells, were determined using CompuSyn software. A CI value $<1$ was considered to be indicative of a synergistic effect. The combination of Sor and Mel showed a synergistic effect in both MIAPaCa-2 and PANC-1 cells, as reflected in the corresponding CI values of 0.05382 (top right) and 0.82872 (bottom right). Data are expressed as means \pm S.D. of triplicate wells $\left({ }^{* * *} \mathrm{P}<0.001\right.$ vs. Sor- or Mel-treated groups). 
potential are known to cause the release of cytochrome $c$ from the inner membrane of the mitochondria into the cytoplasm, thereby initiating the intrinsic apoptosis pathway, we also examined cytochrome $c$ staining. As expected, the combined treatment significantly increased the release of cytochrome $c$, with a concomitant decrease in the co-localization of cytochrome $c$ and mitochondria (Fig. 3B).

To further confirm that the combined treatment induces apoptosis through a mitochondria-mediated pathway, we analyzed expression of mitochondrial proteins that regulate apoptosis. Upon treatment with sorafenib or melatonin, the anti-apoptotic factors, the expression of Bcl-2, Survivin, Mcl-1, and XIAP were suppressed, whereas the proapoptotic factor PARP exhibited greater cleavage in the combined treatment group than either single agent treatment group (Fig. 3D), resulting in an increase in cleaved caspase-3, a dominant player in apoptosis (Fig. 3C). Collectively, our results strongly suggest that the synergistic effects of combined treatment on apoptosis are mediated by the mitochondrial pathway in PDAC cells.

Sorafenib alone and in combination with melatonin did not inhibit the RAF/MEK/ERK pathway and RAF heterodimerization

To investigate the mechanisms by which the combination of sorafenib and melatonin caused anticancer activity in PDAC, we first tested the effect on the RAF/MEK/ERK pathway, the target of the antiproliferative activity of sorafenib [27]. Unexpectedly, both sorafenib alone and in combination with melatonin activated rather than inhibited the RAF/MEK/ ERK pathway, as evidenced by increased levels of p-CRAF, p-MEK, and p-ERK (Fig. 4A). Similar results were obtained in other cancer cells harboring KRAS mutant as shown in Fig. $4 \mathrm{~B}$, consistent with the contradictory effects of sorafenib on the RAF/MEK/ERK pathway

Fig. 2. Combined treatment with Sor and Mel synergistically induces apoptosis. (A) Induction of apoptosis in MIAPaCa-2 cells by the combination of Sor and Mel was determined by TUNEL staining. Data are expressed as means \pm S.D. from three experiments $\left({ }^{*} \mathrm{P}<0.05\right.$ vs. the Sor-treated group; ${ }^{* *} \mathrm{P}<0.01$ vs. the Meltreated group). (B) Annexin-V (red) with DAPI (blue) staining of MIAPaCa-2 cells exposed to Sor and Mel for $24 \mathrm{~h}\left({ }^{*} \mathrm{P}<0.05\right.$ vs. Sor- or Meltreated groups). (C) MIAPaCa-2 cells were treated with Sor and Mel for $24 \mathrm{~h}$. The cell cycle distribution was then assessed by flow cytometry, and the sub- $\mathrm{G}_{1}$ population was analyzed (*** $\mathrm{P}<0.001$ vs. Sor- or Mel-treated groups).

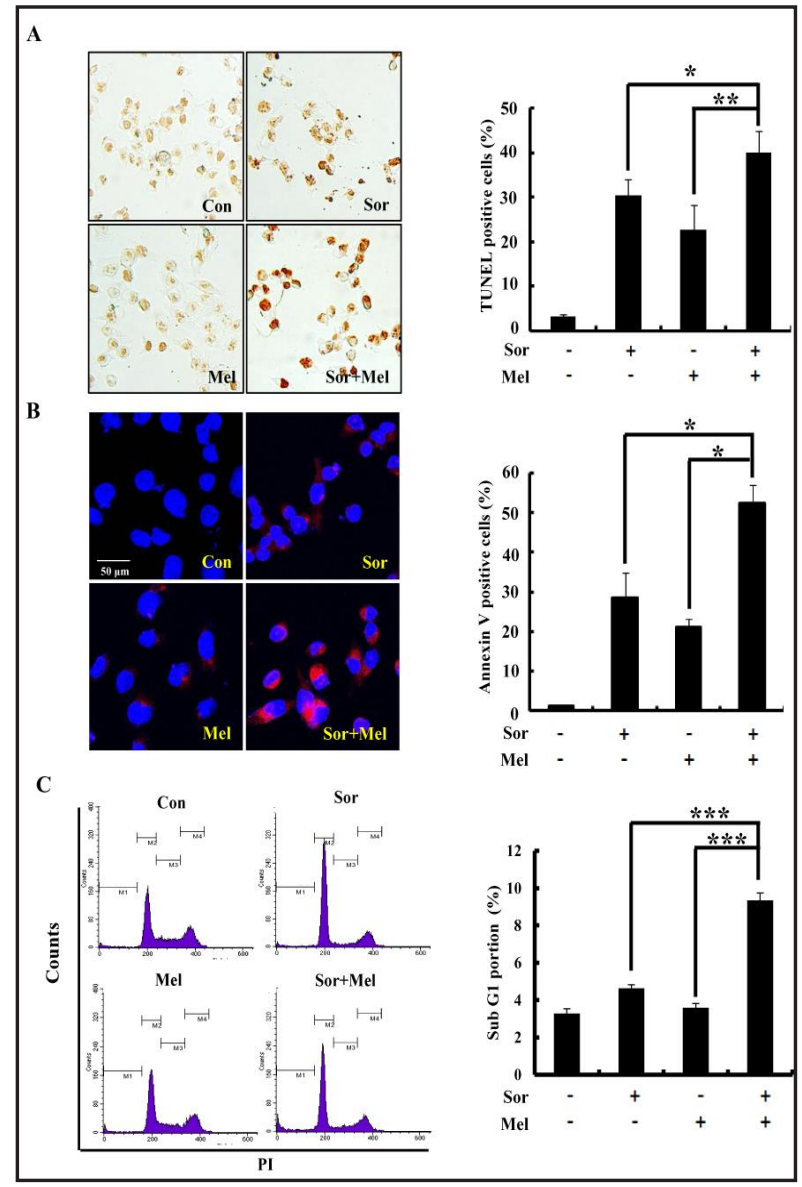


in PDAC cells containing KRAS mutants. In addition to critical cytoplasmic functions, CRAF in mitochondria is also essential for the regulation of mitochondrial shape and cellular distribution [28]. In addition, co-localization of CRAF with p-DAPK (death-associated protein kinase) in the mitochondria facilitates mitochondrial remodeling [28]. Indeed, recent studies on renal cell carcinoma have shown that combined treatment of sorafenib and another RAF inhibitor induces anticancer effects by targeting mitochondrial CRAF [29]. Therefore, we isolated mitochondria and examined mitochondrial CRAF as well as DAPK phosphorylation. However, contrary to expectation, neither sorafenib nor combined treatment decreased the mitochondrial activity of CRAF or DAPK (Fig. 4C).

Because RAF dimerization is a critical determinant of the effects of RAF inhibitors [30], we next investigated whether the combination of sorafenib and melatonin inhibited RAF dimerization in PDAC cells. Co-immunoprecipitation analyses showed that neither combination treatment nor sorafenib alone reduced BRAF-CRAF heterodimerization, but instead increased it, which was further validated by in situ PLA assays (Fig. 4D).

Combination of sorafenib and melatonin inhibited PDGFR- $\beta$-STAT3 pathway in PDAC cells

Collectively, these results indicate that the effects of combined treatment of sorafenib and melatonin are not attributable to actions on RAS/RAF/MEK signaling, mitochondrial RAF, or RAF dimerization, suggesting the involvement of other signaling pathways. To identify anticancer mechanisms that are regulated by sorafenib and melatonin in PDAC, we investigated the activation (phosphorylation) status of 49 different RTKs by performing phospho-RTK analyses. Among tested RTKs, PDGFR- $\beta$ showed the most significant decrease in phosphorylation in response to treatment with sorafenib alone or together with melatonin (Fig. 5A). In addition, we performed a phospho-kinase analysis to determine which other kinases are regulated by sorafenib and its combination. Notably, among the 43

Fig. 3. Combined treatment with Sor and Mel induces mitochondrial apoptosis. (A) Fluorescence images of JC-1 aggregates (red) and monomers in MIAPaCa-2 cells after treatment with Sor and Mel for $16 \mathrm{~h}$. Results were analyzed by plotting the ratio of depolarized cells to polarized cells $\left({ }^{*} \mathrm{P}<0.05\right.$ vs. the Sor-treated group; ${ }^{* *} \mathrm{P}<0.01$ vs. the Mel-treated group). (B) After treatment with Sor and/or Mel for 12 h, MIAPaCa-2 cells were stained with anti-cytochrome c antibody, MitoTracker and DAPI, and analyzed under an Olympus confocal laser-scanning microscope. Results were quantified as the percentage of cells that showed cytochrome c release, expressed as means \pm S.D. from three experiments $\left({ }^{* * *} \mathrm{P}<0.001\right.$ vs. Sor- or Mel-treated groups). (C) Fluorescence images of cleaved caspase-3 (red) after treatment of MIAPaCa-2 cells with Sor and/or Mel for 24 h. (D) MIAPaCa-2 cells were treated with Sor and/or Mel for $10 \mathrm{~h}$. Cell lysates were prepared and analyzed by Western blotting for Bcl-2, survivin, $\mathrm{Mcl}-1$, XIAP, and PARP.

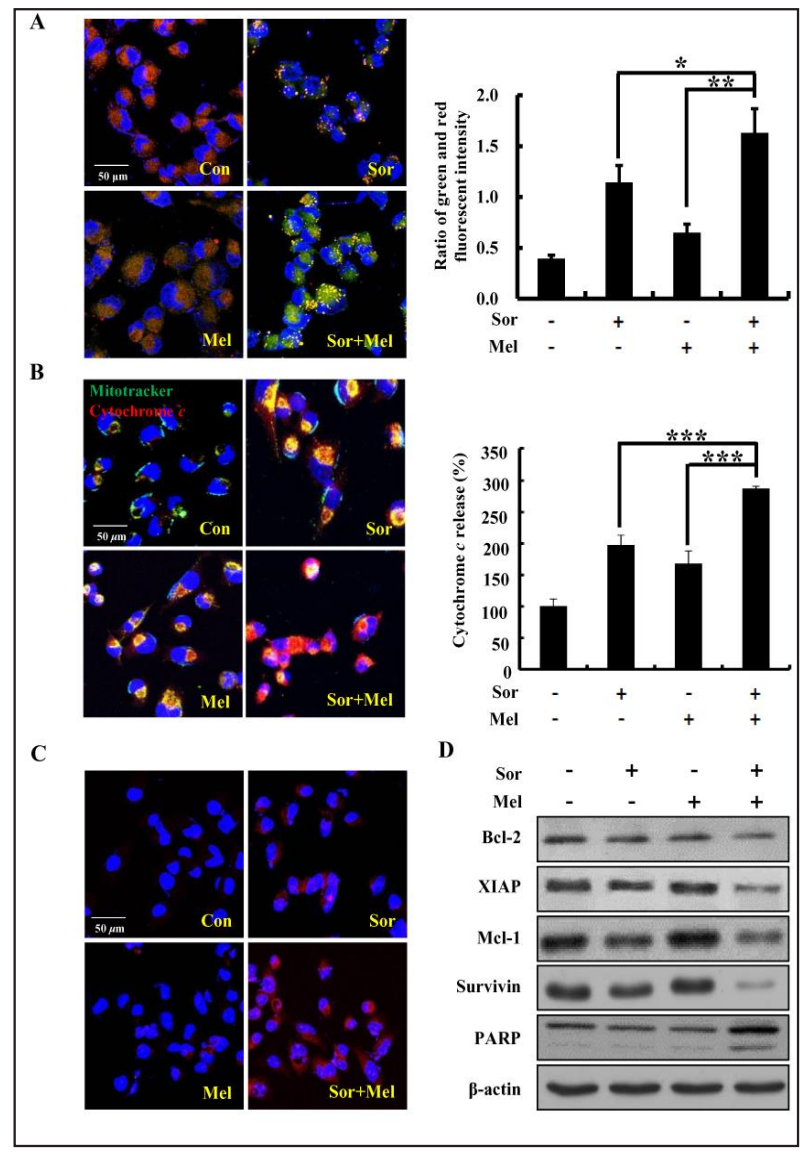

\section{KARGER}




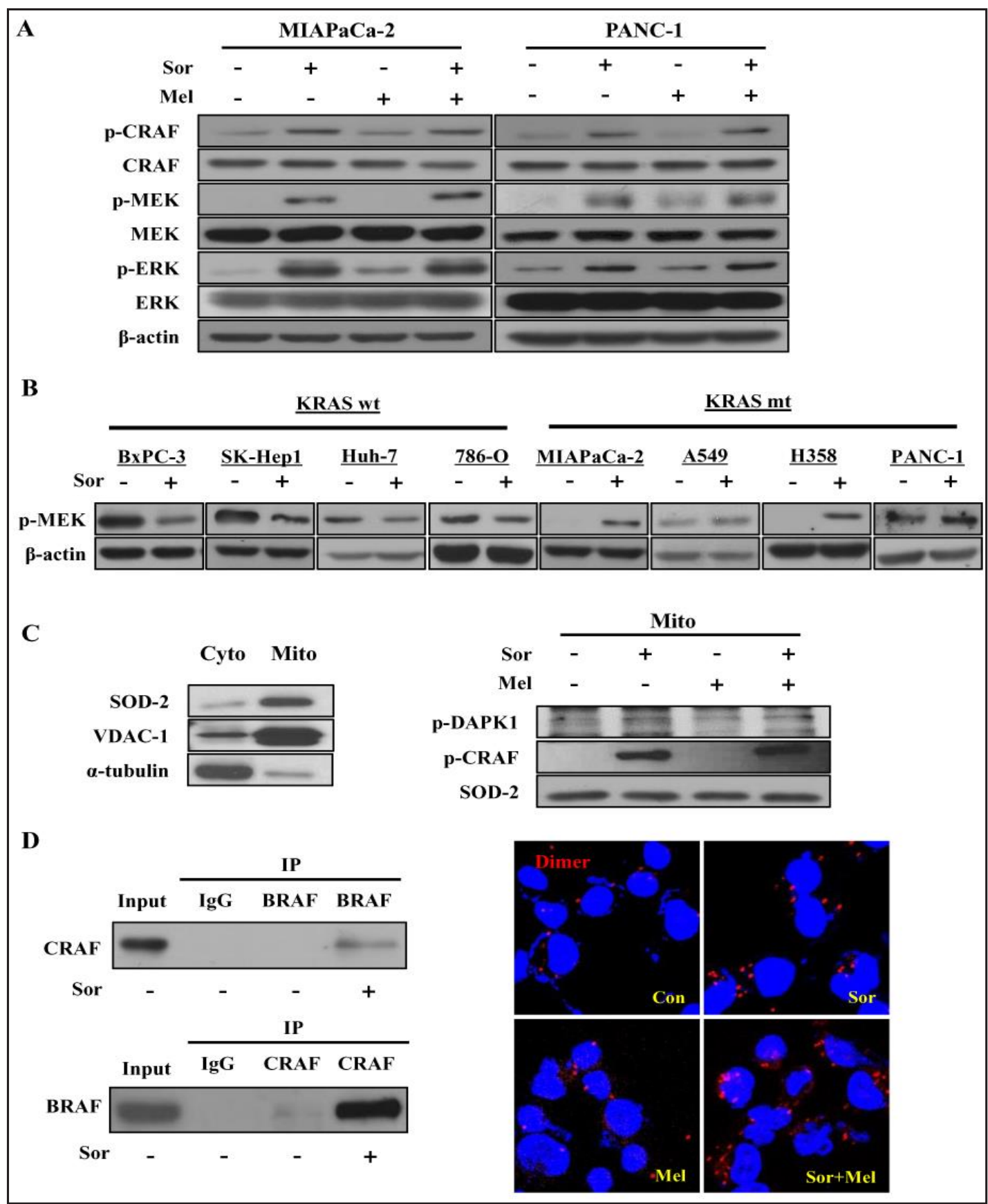

Fig. 4. Sor alone or combination with Mel did not suppress the canonical RAF/MEK/ERK pathway and RAF heterodimerization. (A) MIAPaCa-2 and PANC-1 cells were treated with Sor and/or Mel for 6 h. Cell lysates were prepared and analyzed by Western blotting for levels of phosphorylated and total CRAF, MEK, and ERK. (B) KRAS wild-type cells (BxPC-3, SK-Hep1, Huh-7, and 786-0), and KRAS mutant type cells (MIAPaCa-2, A549, H358, and PANC-1) were treated with Sor for $6 \mathrm{~h}$. Cell lysates were prepared and analyzed by Western blotting for p-MEK. (C) Cytosol (Cyto) and Mitochondria (Mito) were isolated from MIAPaCa-2 cells and verified using the mitochondria-specific markers, SOD-2 and VDAC-1 (left). Levels of p-DAPK1 and p-CRAF in mitochondria of MIAPaCa-2 cells were measured by Western blotting analysis (right). (D) MIAPaCa-2 cells were treated with Sor for $6 \mathrm{~h}$ prior to lysis. Endogenous CRAF and BRAF were individually immunoprecipitated and probed for the binding of endogenous BRAF and CRAF, respectively (left). MIAPaCa-2 cells were treated with Sor and/or Mel for $6 \mathrm{~h}$ prior to fixation. Red foci indicate binding interactions in the PLA assay. Cell nuclei were stained with DAPI (right). 


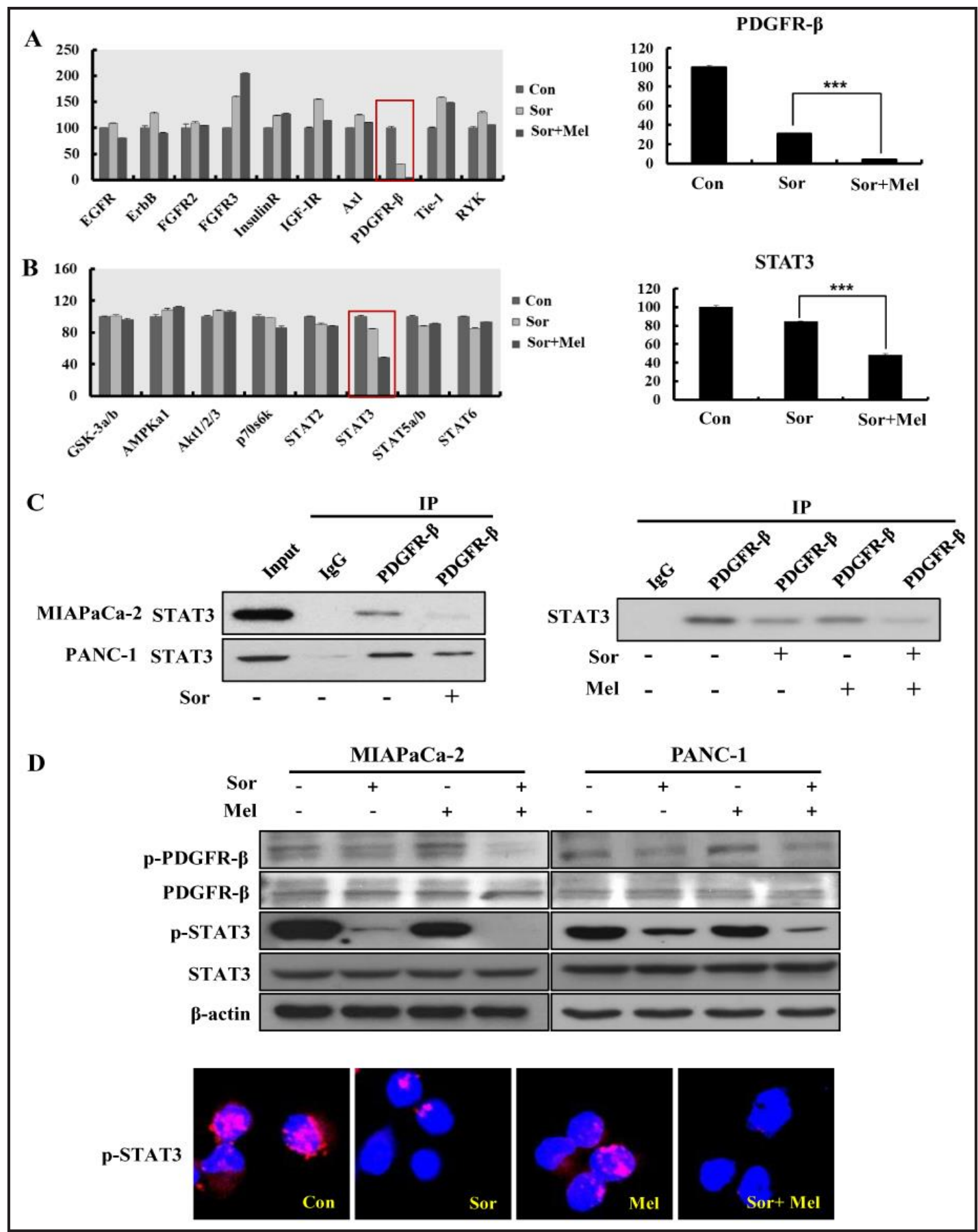

Fig. 5. Inhibition of the PDGFR- $\beta$-STAT3 pathway in PDAC cells by combined treatment of Sor and Mel. (A) After MIAPaCa-2 cells were treated with Sor and/or Mel for $6 \mathrm{~h}$, the levels of phosphorylated RTKs were analyzed using a Phospho-RTK array. (B) After MIAPaCa-2 cells were treated with Sor and/or Mel for $6 \mathrm{~h}$, the levels of phosphorylated kinases were analyzed using a Phospho-kinase array. (C) MIAPaCa-2 and/or PANC1 cells were treated with Sor and/or Mel for $6 \mathrm{~h}$, and cell lysates were immunoprecipitated with PDGFR- $\beta$ antibody for $16 \mathrm{~h}$, followed by Western blotting with STAT3 antibody. (D) Cell lysates were analyzed by Western blotting for total and phosphorylated PDGFR- $\beta$ and STAT3. After treatment with Sor and/or Mel for $6 \mathrm{~h}$, MIAPaCa-2 cells were immunostained for p-STAT3. Cell nuclei were stained with DAPI to validate the intracellular location of molecules (bottom). 
different kinases tested in this assay, p-STAT3 was the most significantly down-regulated by combined treatment (Fig. 5B). These data were validated by Western blotting analysis and immunoprecipitation, which showed that combined treatment also decreased levels of p-PDGFR- $\beta$ and p-STAT3 and intracellular interaction in both MIAPaCa- 2 and PANC- 1 cell lines (Fig. 5C and D). Furthermore, combined treatment reduced nuclear translocation of p-STAT3 compared with treatment with either agent alone, as observed by immunofluorescence staining (Fig. 5D). These results suggest that the antiproliferative and proapoptotic effects of the combined treatment may be mediated by the PDGFR- $\beta /$ STAT3 pathway in PDAC cells.

Melatonin inhibited activation of STAT-3 through MT in combination treatment in PDAC cells

The physiological activity of melatonin are regulated through its communication with two membrane receptors, melatonin receptor type 1A (MT1) and 1B (MT2), which are coupled to the guanine nucleotide binding proteins (G proteins) [31]. In various types of cancer, melatonin is known to have anti-tumorigenic properties and loss of MT could represent decreased sensitivity to the anti-proliferative properties of melatonin [32, 33]. Thus, we measured expression of melatonin receptors in PDAC cells. As shown in Fig. 6A, the expression of MT1 and MT2 was higher in PDAC cells than in normal cells. Especially, the MT2 expression was significantly elevated in all PDAC cells compared with normal cells; human umbilical endothelial cells (HUVEC) and normal pancreatic epithelial cells (HPNE). Based on the evidences that melatonin inhibited activation of STAT-3 and MT was associated with activation of STAT-3 [34, 35], we next identified that melatonin inhibited MT-mediated STAT3 activation in PDAC cells. For this experiment, PDAC cells were treated with melatonin in the presence or absence of luzindole, a MT1/MT2 antagonist. As expected, the decrease of STAT3 expression by melatonin was completely rescued by MT inhibition of luzindole, suggesting that down-regulation of STAT3 by melatonin in combination treatment is mediated via MT as well as PDGFR- $\beta$ (Fig. 6B).

Combination of sorafenib and melatonin suppressed tumor growth in PDAC xenograft models

To test the effect of combined treatment on tumor growth in vivo, we used a MIAPaCa-2 xenograft model. As shown in Fig. 7, tumor growth in mice treated with melatonin or sorafenib alone was only slightly delayed compared with the control group. In contrast, combination treatment resulted in tremendous antitumor effects. In addition, no significant changes in body weight were observed, indicating that the combination treatment regimen possesses a good safety profile, even with multiple administrations. To further confirm that the combination effectively inhibits tumor growth by inducing apoptosis, we investigated the expression level of cleaved caspase-3 and determined the number of TUNEL-positive cells in pancreatic tumor tissues. The combined treatment increased cleaved caspase- 3 expression and the number of TUNEL-positive cells compared with the control and single-treatment groups. Moreover, combination treatment significantly attenuated intratumoral expression of p-PDGFR- $\beta$ and p-STAT3 (Fig. 7B).

\section{Discussion}

PDAC is an aggressive malignancy, reflecting its extensive local invasion, subsequent development of metastasis, and resistance to chemo- and radiotherapy. Although gemcitabine has been proposed as a standard chemotherapy, the median survival with this treatment paradigm in advanced PDAC is only $\sim 5.4$ months. With the failure of single-agent chemotherapy, combination therapy has progressively gained research attention. However, previous studies have demonstrated that gemcitabine combined with common anticancer drugs yields poor responses or limited therapeutic effects with prominent side effects [4]. To date, a number of research groups have reported that combination chemotherapy with dietary supplements may lead to beneficial effects in cancer treatment, producing better 
Fig. 6. Mel enhances inhibition of STAT3 via MT in combination treatment with Sor in PDAC cells. (A) Expression pattern of MT1/MT2 analyzed in various PDAC cell lines (AsPC-1, BxPC3, MIAPaCa-2, PANC-1, and HPAC) and normal cell lines (HPNE and HUVEC). (B and C) Expression of STAT-3 by Mel was disrupted by luzindole (Luz) treatment, a MT antagonist. MIAPaCa-2 and PANC-1 PDAC cells were serumstarved for $16 \mathrm{~h}$, and then were treated with Mel ( $2 \mathrm{mM}, 6 \mathrm{~h}$ ) after pretreatment of luzindole $(10 \mu \mathrm{M}, 3 \mathrm{~h})$. Expression of STAT3 was examined by Western blot analysis and immunofluorescences.

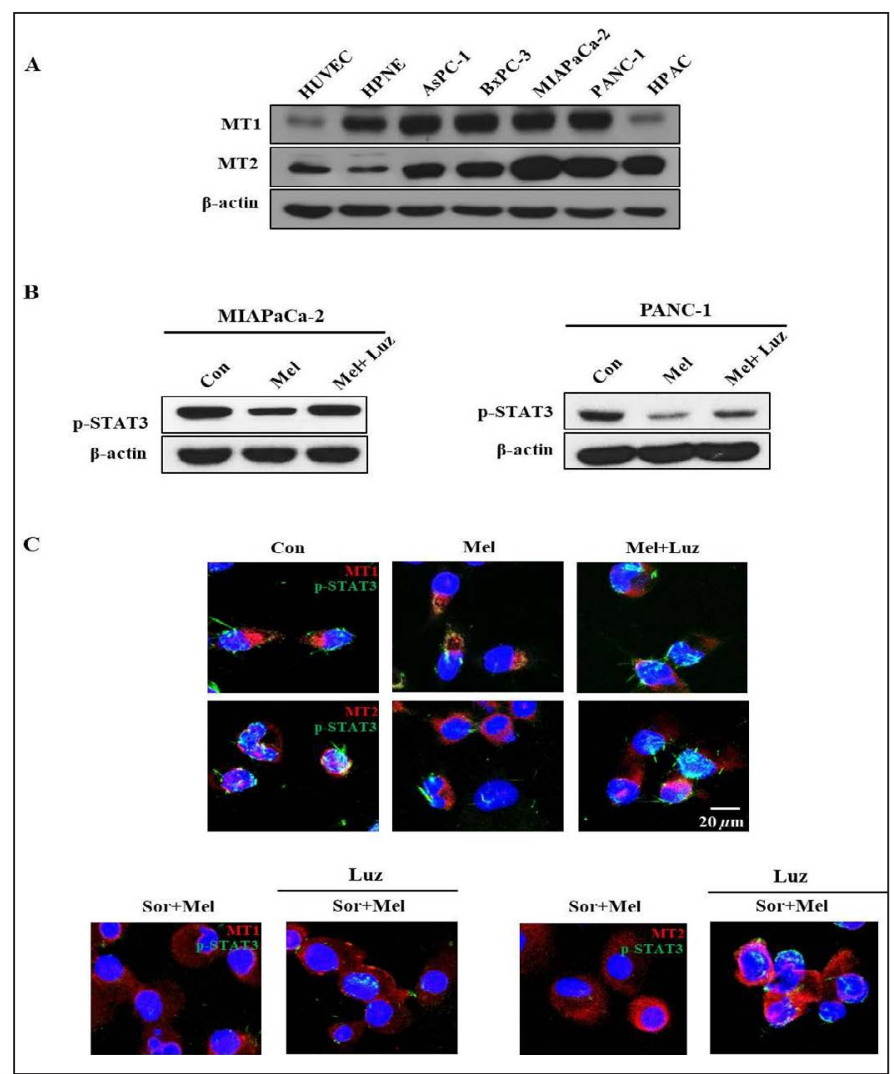

Fig. 7. Antitumor effects of combined treatment with Sor and Mel on MIAPaCa-2 xenograft models in athymic nude mice. (A) Effects of Sor $(10 \mathrm{mg} /$ $\mathrm{kg}$ ), Mel (40 mg/kg), and combination treatment for 27 days on MIAPaCa-2 xenograft tumor growth and body weight. (B) Histological analysis of pancreatic xenograft tumor tissue by hematoxylin and eosin (H\&E) staining, immunohistochemical detection of p-PDGFR- $\beta$, p-STAT3, PCNA and cleaved caspase-3, and TUNEL staining. (C) Scheme for how Mel in combination with Sor induces apoptosis and inhibits the growth of PDAC cells. Mel enhances apoptosis and suppression of cell survival in combination treatment mainly by the inhibition of PDGFR- $\beta$ mediated STAT3 and MT-mediated STAT3. Original magnification $\times 400$. Data are represented as the mean \pm S.D. ${ }^{*} \mathrm{P}<0.05,{ }^{* *} \mathrm{P}<0.01$, and ${ }^{* * *} \mathrm{P}<0.001$ vs Control).

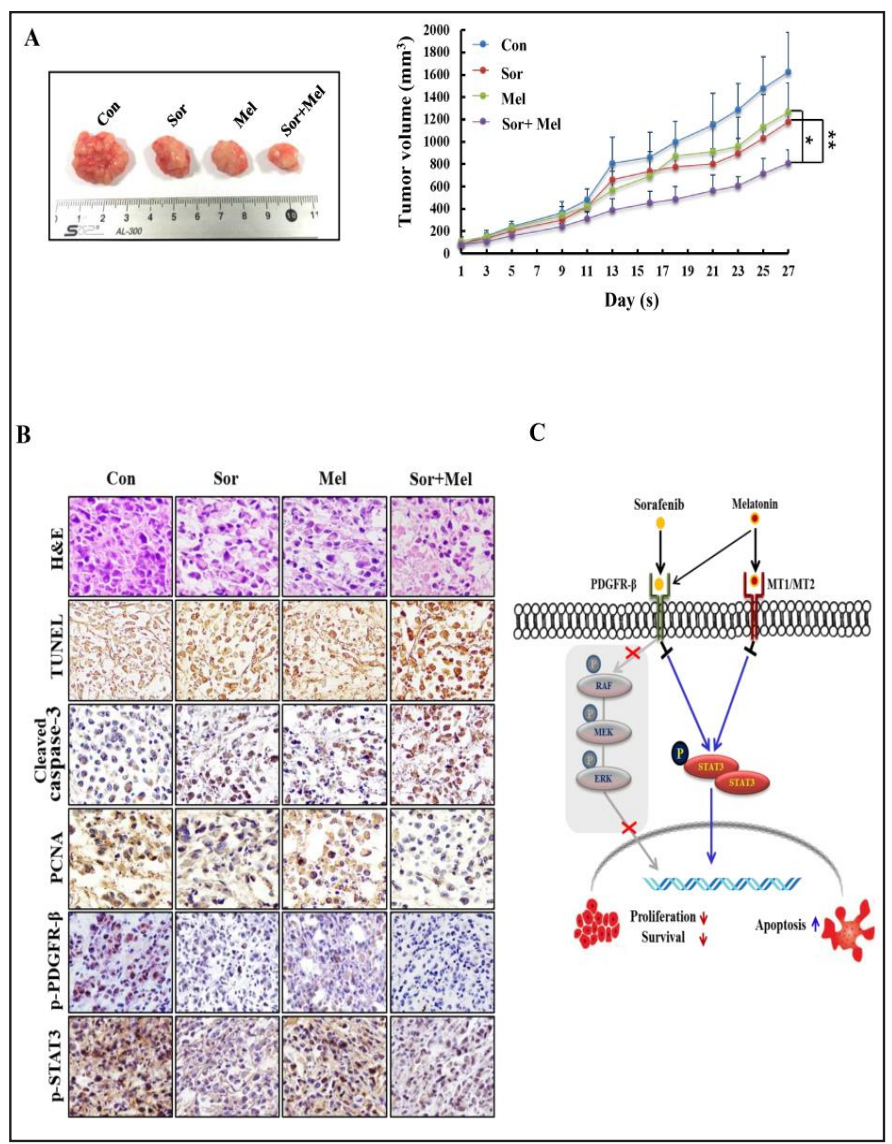


therapeutic efficacy with fewer side effects $[8,13,14]$. In addition, the combination of sorafenib with other agents has also shown noteworthy results in preclinical studies [14, 36]. However, studies of sorafenib in PDAC, alone or in combination with other agents, are limited.

Given that melatonin appears to exert anticancer effects in different types of cancer cells $[36,37]$, we hypothesized that the combination of sorafenib and melatonin might achieve synergistic effects in pancreatic cells, and further investigated its mechanism of action. We found that combined treatment significantly inhibited the growth of PDAC cells compared with treatment with either agent alone. As shown in CI values, simultaneous treatment with sorafenib $(10 \mu \mathrm{M})$ and melatonin $(2 \mathrm{mM})$ showed the highest synergistic effects in PDAC cells. Since each sorafenib or melatonin have been reported to induce apoptosis $[8,21]$, we also investigated whether the combination treatment causes a synergic apoptotic effect. TUNEL staining showed that the combination induced significant apoptosis, as evidenced by increased TUNEL-positive nuclear fragmentation. In addition, an Annexin-V assay revealed the induction of DNA damage after the combined treatment. These results were further confirmed by an assessment of cell-cycle distribution, which revealed a $\sim 2$-fold increase in the sub- $\mathrm{G}_{1}$, apoptotic cell population.

In general, apoptosis is classified into two different pathways: the extrinsic pathway, mediated by death receptors, and the intrinsic pathway, mediated by mitochondrial factors. In case of the intrinsic apoptotic pathway, a loss of mitochondrial membrane potential, permeabilization of theoutermitochondrial membrane, and consequentrelease ofapoptogenic factors, such as cytochrome $c$ and apoptosis-inducing factor (AIF) are characterized. There are also increasing reports that the combination of sorafenib with other agents triggers the intrinsic mitochondrial apoptotic pathway [9]. We previously reported that the combination of sorafenib and a PI3K inhibitor induces mitochondria-mediated apoptosis by decreasing mitochondrial membrane potential and releasing cytosolic cytochrome $c$ in PDAC cells [38]. Here, we extended this analysis by investigating the involvement of mitochondrial membrane potential in the effects of combined treatment on apoptosis by testing changes in membrane potential and immunofluorescence staining for cytochrome $c$. We found that the combined treatment synergistically reduced mitochondrial membrane potential and significantly increased cytochrome $c$. To confirm these results, we investigated the expression of the Bcl2 family members Bcl-2, Survivin, Mcl-1 and XIAP, as well as inhibitory apoptosis proteins (IAPs) that contribute to mitochondria-mediated apoptosis [39]. These analyses showed that combined treatment significantly decreased the expression of Bcl-2, Survivin, Mcl-1 and XIAP, while increasing cleaved caspase- 3 and cleaved PARP levels in PDAC cells. Collectively, our findings demonstrate that the synergistic apoptotic effects of the combined treatment may be regulated by the mitochondrial-mediated apoptotic pathway in PDAC cells.

Sorafenib has been approved as first-line chemotherapy for the clinical management of primary hepatic cellular carcinoma and kidney cancer, and its major target has been identified as RAF, which is involved in the RAF/MEK/ERK signaling cascade [7, 40]. Because the RAF/MEK/ERK pathway is commonly activated in PDAC owing to a high frequency of KRAS mutations, we examined common elements of the RAF/MEK/ERK pathway in both whole-cell lysates and mitochondria after the combined treatment. Notably, it has been shown that mitochondrial p-CRAF, an important modulator of mitochondria structural remodeling, is down-regulated by RAF inhibitors including sorafenib, in renal cell carcinoma [29]. However, we found that neither sorafenib alone nor its combination with melatonin negatively regulated the RAF/MEK/ERK pathway, as evidenced by an increase rather than a decrease in both cytosolic and mitochondrial p-CRAF. This activation of RAF/MEK/ ERK signaling in PDAC is thought to reflect the presence of KRAS mutants in these cancer cells. These results are supported by a study by Holderfield et al, which showed that RAF inhibitors including sorafenib, are less potent inhibitors of RAF/MEK/ERK signaling in cells with activating RAS mutations [41]. Accordingly, we suggest that the antiproliferative and proapoptotic effects of sorafenib alone or combination with melatonin are independent of the RAF/MEK/ERK pathway in PDAC cells (Fig. 4B). Accumulating evidences suggest that 
RAF inhibitors promote dimerization of RAF in cells expressing mutated KRAS, leading to reconstitution of the MAPK signaling pathway $[30,42]$. On the other hand, it is well known that KRAS is the most frequently mutated gene in PDAC (up to 95\%), but there are few reports of the occurrence of RAF dimerization, and there is still no evidence that sorafenib affects RAF dimerization in PDACs. Hence, we investigated whether effects of melatonin and sorafenib in combination involve inhibition of RAF dimerization in PDAC. Contrary to expectation, we found that sorafenib alone increased RAF dimerization in PDAC cells, and its combination with melatonin did not block RAF dimerization (Fig. 4D). These results indicate that the anticancer effect of the combined treatment is not related to inhibition of RAS/RAF/ MEK signaling, mitochondria RAF, or RAF dimerization.

In addition to the RAF/MEK/ERK pathway, sorafenib is known to target various RTKs, including PDGFR- $\beta$, VEGFR, c-Kit, and Flt-3 [5]. Thus, to further elucidate the detailed molecular mechanisms underlying the anticancer activity of the combined treatment, we used phospho-RTKs and phospho-kinases array kits, which are representative factors involved in cancer signaling pathways. Among RTKs examined, PDGFR- $\beta$ was the most significantly decreased by either sorafenib alone or together with melatonin. Additionally, several other effectors including STAT family members and PI3K/AKT, are known to be targets of sorafenib $[25,43,44]$, and constitutive STAT3 activation has been shown to be critical for cancer initiation, progression, invasion, and motility of carcinoma cells [45]. In addition, blockade of constitutively STAT3 pathway has inhibited growth of human PDAC [46].

In line with these observations, our analysis of phospho-kinases revealed that the combined treatment regimen decreased p-STAT3 levels. Notably, PDGFR- $\beta$ is known to induce STAT3 phosphorylation, and activated STAT3 leads to cell transformation $[47,48]$. Consequently, elevated STAT3 signaling inhibits apoptosis and supports cancer survival, producing a phenotype similar to chemo-resistance [49]. In the current study, sorafenib alone suppressed p-PDGFR- $\beta$ and p-STAT3 levels as well as nuclear translocation of STAT3, and the combination treatment completely blocked the PDGFR- $\beta$ /STAT3 signaling pathway (Fig. 5 and 6). Considering the previous study that sorafenib suppresses STAT3 signaling associated with growth arrest and causes apoptosis [50], it seems that melatonin improves the anticancer activity of sorafenib through PDGFR- $\beta$ /STAT3 pathway, and not the RAF/ MEK/ERK signaling pathway [49].

Melatonin has been reported to bind and activate two distinct receptor types, MT1 and MT2 [51]. MT1 and MT2 are expressed in various organs and neoplastic cells such as cancer [52]. In numbers of studies, melatonin has shown anti-cancer properties, and loss of MT expression has decreased sensitivity to the anti-proliferative properties of melatonin [32, 33]. Indeed, overexpression of MT1 melatonin receptor enhanced anti-proliferative effect of melatonin in human breast cancer cells [51]. Also, MT is linked to the modulation of STAT3 $[53,54]$ and inhibition of MT expression has been reported to down-regulate activation of STAT-3 [55]. In addition, melatonin has shown to inhibit tumorigenicity via STAT3 signaling [35]. Considering significant role between MT and STAT3, we expected that melatonin bound with MT in PDAC cells, which inhibited expression of p-STAT-3. Interestingly, we observed that MT1/MT2 was highly expressed in five PDAC cells compared with normal cells, and down-regulation of STAT3 by melatonin was recovered via MT inhibition by MT1/MT2 antagonist. These results imply that melatonin enhances combination effect with sorafenib by inhibition of STAT- 3 via MT and PDGFR- $\beta$.

A trend similar to in vitro results was confirmed in a mouse xenograft model. Here, sorafenib treatment alone caused negligible inhibition of tumor growth, whereas combination treatment of sorafenib and melatonin exerted potent antitumor effects that surpassed those of either single treatment, confirming the sensitizing effect of melatonin on pancreatic xenografts (Fig. 7A). Moreover, combination treatment showed a good safety profile, similar to either sorafenib or melatonin alone group. Notably, the potent anticancer and proapoptotic effects induced by combination treatment were associated with inhibition of PDGFR- $\beta$ /STAT3 signaling in tumor tissue (Fig. 7B).

\section{KARGER}




\section{Cellular Physiology Cell Physiol Biochem 2018;47:1751-1768

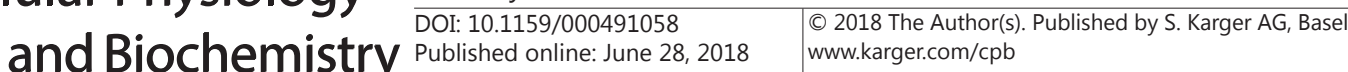

Fang et al.: Synergistic Effect of Sorafenib and Melatonin

\section{Conclusion}

Our data show that melatonin in combination with sorafenib synergistically inhibited the growth of PDAC cells and induced mitochondrial-mediated apoptosis through inhibition of the PDGFR- $\beta$ /STAT3 pathway and MT-mediated STAT-3. Our findings provide new insight into potential therapeutic strategies in PDAC and lay the foundation for possible future clinical regimens.

\section{Acknowledgements}

This research was supported by the National Research Foundation (NRF) Grant (2015R1A2A1A10054108, 2014M3C1A3051476), and the Korea Health Technology R\&D Project (HI15C0554), Ministry of Health and Welfare, Republic of Korea.

\section{Disclosure Statement}

No conflict of interests exists.

\section{References}

1 Michl P, Gress TM: Current concepts and novel targets in advanced pancreatic cancer. Gut 2013;62:317326.

2 Zhang JJ, Zhu Y, Zhang XF, Liu DF, Wang Y, Yang C, Shi GD, Peng YP, Zhang K, Tian L, Miao Y, Jiang KR: Yin Yang-1 suppresses pancreatic ductal adenocarcinoma cell proliferation and tumor growth by regulating SOX2OT-SOX2 axis. Cancer Lett 2017;408:144-154.

-3 Kang MJ, Jang JY, Kim SW: Surgical resection of pancreatic head cancer: What is the optimal extent of surgery? Cancer Lett 2016;382:259-265.

4 Zhao X, Wang X, Fang L, Lan C, Zheng X, Wang Y, Zhang Y, Han X, Liu S, Cheng K, Zhao Y, Shi J, Guo J, Hao J, Ren H, Nie G: A combinatorial strategy using YAP and pan-RAF inhibitors for treating KRAS-mutant pancreatic cancer. Cancer Lett 2017;402:61-70.

5 Sun T, Liu H, Ming L: Multiple Roles of Autophagy in the Sorafenib Resistance of Hepatocellular Carcinoma. Cell Physiol Biochem 2017;44:716-727.

6 Keating GM, Santoro A: Sorafenib: a review of its use in advanced hepatocellular carcinoma. Drugs 2009;69:223-240.

7 Ulivi P, Arienti C, Amadori D, Fabbri F, Carloni S, Tesei A, Vannini I, Silvestrini R, Zoli W: Role of RAF/MEK/ ERK pathway, p-STAT-3 and Mcl-1 in sorafenib activity in human pancreatic cancer cell lines. J Cell Physiol 2009;220:214-221.

-8 Wei G, Wang M, Carr BI: Sorafenib combined vitamin K induces apoptosis in human pancreatic cancer cell lines through RAF/MEK/ERK and c-Jun NH2-terminal kinase pathways. J Cell Physiol 2010;224:112-119.

- 9 Kim YS, Jin HO, Seo SK, Woo SH, Choe TB, An S, Hong SI, Lee SJ, Lee KH, Park IC: Sorafenib induces apoptotic cell death in human non-small cell lung cancer cells by down-regulating mammalian target of rapamycin (mTOR)-dependent survivin expression. Biochem Pharmacol 2011;82:216-226.

10 Hainsworth JD, Waterhouse DM, Penley WC, Shipley DL, Thompson DS, Webb CD, Anthony Greco F: Sorafenib and everolimus in advanced clear cell renal carcinoma: a phase I/II trial of the SCRI Oncology Research Consortium. Cancer Invest 2013;31:323-329.

11 Rimassa L, Pressiani T, Boni C, Carnaghi C, Rota Caremoli E, Fagiuoli S, Foa P, Salvagni S, Cortesi E, Chiara Tronconi M, Personeni N, Bozzarelli S, Chiara Banzi M, Fanello S, Romano Lutman F, Giordano L, Santoro A: A phase II randomized dose escalation trial of sorafenib in patients with advanced hepatocellular carcinoma. Oncologist 2013;18:379-380. 


\section{Cellular Physiology Cell Physiol Biochem 2018;47:1751-1768 \begin{tabular}{l|l} 
DOI: 10.1159/000491058 & $\begin{array}{l}\text { O 2018 The Author(s). Published by S. Karger AG, Basel } \\
\text { www.karger.com/cpb }\end{array}$ \\
\hline
\end{tabular}}

Fang et al.: Synergistic Effect of Sorafenib and Melatonin

12 Chen CH, Chen MC, Wang JC, Tsai AC, Chen CS, Liou JP, Pan SL, Teng CM: Synergistic interaction between the HDAC inhibitor, MPT0E028, and sorafenib in liver cancer cells in vitro and in vivo. Clin Cancer Res 2014;20:1274-1287.

13 Du W, Zhou JR, Wang DL, Gong K, Zhang QJ: Vitamin K1 enhances sorafenib-induced growth inhibition and apoptosis of human malignant glioma cells by blocking the Raf/MEK/ERK pathway. World J Surg Oncol 2012;10:60.

14 Benitez A, Yates TJ, Shamaldevi N, Bowen T, Lokeshwar VB: Dietary supplement hymecromone and sorafenib: a novel combination for the control of renal cell carcinoma. J Urol 2013;190:285-290.

15 Liu Z, Gan L, Luo D, Sun C: Melatonin promotes circadian rhythm-induced proliferation through Clock/ histone deacetylase 3/c-Myc interaction in mouse adipose tissue. J Pineal Res 2017;62:e12383

16 Tomov B, Popov D, Tomova R, Vladov N, Den Otter W, Krastev Z: Therapeutic response of untreatable hepatocellular carcinoma after application of the immune modulators IL-2, BCG and melatonin. Anticancer Res 2013;33:4531-4535.

17 Ge D, Dauchy RT, Liu S, Zhang Q, Mao L, Dauchy EM, Blask DE, Hill SM, Rowan BG, Brainard GC, Hanifin JP, Cecil KS, Xiong Z, Myers L, You Z: Insulin and IGF1 enhance IL-17-induced chemokine expression through a GSK3B-dependent mechanism: a new target for melatonin's anti-inflammatory action. J Pineal Res 2013;55:377-387.

18 Borin TF, Arbab AS, Gelaleti GB, Ferreira LC, Moschetta MG, Jardim-Perassi BV, Iskander AS, Varma NR, Shankar A, Coimbra VB, Fabri VA, de Oliveira JG, Zuccari DA: Melatonin decreases breast cancer metastasis by modulating Rho-associated kinase protein-1 expression. J Pineal Res 2016;60:3-15.

19 Cini G, Neri B, Pacini A, Cesati V, Sassoli C, Quattrone S, D’Apolito M, Fazio A, Scapagnini G, Provenzani A, Quattrone A: Antiproliferative activity of melatonin by transcriptional inhibition of cyclin D1 expression: a molecular basis for melatonin-induced oncostatic effects. J Pineal Res 2005;39:12-20.

20 Kajdaniuk D, Marek B, Kos-Kudla B: Influence of adjuvant chemotherapy with cyclophosphamide, methotrexate and 5-fluorouracil on plasma melatonin and chosen hormones in breast cancer premenopausal patients. J Clin Pharm Ther 2001;26:297-301.

-21 Messina G, Lissoni P, Marchiori P, Bartolacelli E, Brivio F, Magotti L: Enhancement of the efficacy of cancer chemotherapy by the pineal hormone melatonin and its relation with the psychospiritual status of cancer patients. J Res Med Sci 2010;15:225-228.

22 Kesik V, Kurt B, Tunc T, Karslioglu Y, Citak EC, Kismet E, Koseoglu V: Melatonin ameliorates doxorubicininduced skin necrosis in rats. Ann Plast Surg 2010;65:250-253.

23 Gonzalez A, del Castillo-Vaquero A, Miro-Moran A, Tapia JA, Salido GM: Melatonin reduces pancreatic tumor cell viability by altering mitochondrial physiology. J Pineal Res 2011;50:250-260.

-24 Uguz AC, Cig B, Espino J, Bejarano I, Naziroglu M, Rodriguez AB, Pariente JA: Melatonin potentiates chemotherapy-induced cytotoxicity and apoptosis in rat pancreatic tumor cells. J Pineal Res 2012;53:9198.

25 Lin S, Hoffmann K, Gao C, Petrulionis M, Herr I, Schemmer P: Melatonin promotes sorafenib-induced apoptosis through synergistic activation of JNK/c-jun pathway in human hepatocellular carcinoma. J Pineal Res 2017; 62:e12398

-26 Chou TC, Talalay P: Quantitative analysis of dose-effect relationships: the combined effects of multiple drugs or enzyme inhibitors. Adv Enzyme Regul 1984;22:27-55.

-27 Saidak Z, Giacobbi AS, Louandre C, Sauzay C, Mammeri Y, Galmiche A: Mathematical modelling unveils the essential role of cellular phosphatases in the inhibition of RAF-MEK-ERK signalling by sorafenib in hepatocellular carcinoma cells. Cancer Lett 2017;392:1-8.

28 Wang HG, Rapp UR, Reed JC: Bcl-2 targets the protein kinase Raf-1 to mitochondria. Cell 1996;87:629-638.

29 Tsai YT, Chuang MJ, Tang SH, Wu ST, Chen YC, Sun GH, Hsiao PW, Huang SM, Lee HJ, Yu CP, Ho JY, Lin HK, Chen MR, Lin CC, Chang SY, Lin VC, Yu DS, Cha TL: Novel Cancer Therapeutics with Allosteric Modulation of the Mitochondrial C-Raf-DAPK Complex by Raf Inhibitor Combination Therapy. Cancer Res 2015;75:35683582 .

-30 Zhang C, Spevak W, Zhang Y, Burton EA, Ma Y, Habets G, Zhang J, Lin J, Ewing T, Matusow B, Tsang G, Marimuthu A, Cho H, Wu G, Wang W, Fong D, Nguyen H, Shi S, Womack P, Nespi M, Shellooe R, Carias H, Powell B, Light E, Sanftner L, Walters J, Tsai J, West BL, Visor G, Rezaei H, Lin PS, Nolop K, Ibrahim PN, Hirth P, Bollag G: RAF inhibitors that evade paradoxical MAPK pathway activation. Nature 2015;526:583-586. 


\section{Cellular Physiology Cell Physiol Biochem 2018;47:1751-1768 \begin{tabular}{l|l} 
and Biochemistry Published online: June 28, 2018 & $\begin{array}{l}\text { (c) } 2018 \text { The Author(s). Published by S. Karger AG, Basel } \\
\text { www.karger.com/cpb }\end{array}$ \\
\hline
\end{tabular}}

-31 Luchetti F, Canonico B, Betti M, Arcangeletti M, Pilolli F, Piroddi M, Canesi L, Papa S, Galli F: Melatonin signaling and cell protection function. FASEB J 2010;24:3603-3624.

-32 Di Bella G, Mascia F, Gualano L, Di Bella L: Melatonin anticancer effects: review. Int J Mol Sci 2013;14:24102430.

-33 Cucina A, Proietti S, D’Anselmi F, Coluccia P, Dinicola S, Frati L, Bizzarri M: Evidence for a biphasic apoptotic pathway induced by melatonin in MCF-7 breast cancer cells. J Pineal Res 2009;46:172-180.

-34 Carbajo-Pescador S, Ordonez R, Benet M, Jover R, Garcia-Palomo A, Mauriz JL, Gonzalez-Gallego J: Inhibition of VEGF expression through blockade of Hif1alpha and STAT3 signalling mediates the antiangiogenic effect of melatonin in HepG2 liver cancer cells. Br J Cancer 2013;109:83-91.

-35 Chen X, Hao A, Li X, Du Z, Li H, Wang H, Yang H, Fang Z: Melatonin inhibits tumorigenicity of glioblastoma stem-like cells via the AKT-EZH2-STAT3 signaling axis. J Pineal Res 2016;61:208-217.

-36 Galuppo R, Maynard E, Shah M, Daily MF, Chen C, Spear BT, Gedaly R: Synergistic inhibition of HCC and liver cancer stem cell proliferation by targeting RAS/RAF/MAPK and WNT/beta-catenin pathways. Anticancer Res 2014;34:1709-1713.

37 Wang J, Xiao X, Zhang Y, Shi D, Chen W, Fu L, Liu L, Xie F, Kang T, Huang W, Deng W: Simultaneous modulation of COX-2, p300, Akt, and Apaf-1 signaling by melatonin to inhibit proliferation and induce apoptosis in breast cancer cells. J Pineal Res 2012;53:77-90.

38 Yun SM, Jung KH, Lee H, Son MK, Seo JH, Yan HH, Park BH, Hong S, Hong SS: Synergistic anticancer activity of HS-173, a novel PI3K inhibitor in combination with Sorafenib against pancreatic cancer cells. Cancer Lett 2013;331:250-261.

-39 Fang Z, Jung KH, Yan HH, Kim SJ, Son MK, Rumman M, Lee H, Kim KW, Yoo HD, Hong SS: CD-200 induces apoptosis and inhibits Bcr-Abl signaling in imatinib-resistant chronic myeloid leukemia with T315I mutation. Int J Oncol 2015;47:253-261.

40 Wilhelm SM, Carter C, Tang L, Wilkie D, McNabola A, Rong H, Chen C, Zhang X, Vincent P, McHugh M, Cao Y, Shujath J, Gawlak S, Eveleigh D, Rowley B, Liu L, Adnane L, Lynch M, Auclair D, Taylor I, Gedrich R, Voznesensky A, Riedl B, Post LE, Bollag G, Trail PA: BAY 43-9006 exhibits broad spectrum oral antitumor activity and targets the RAF/MEK/ERK pathway and receptor tyrosine kinases involved in tumor progression and angiogenesis. Cancer Res 2004;64:7099-7109.

41 Holderfield M, Nagel TE, Stuart DD: Mechanism and consequences of RAF kinase activation by smallmolecule inhibitors. Br J Cancer 2014;111:640-645.

42 Hatzivassiliou G, Song K, Yen I, Brandhuber BJ, Anderson DJ, Alvarado R, Ludlam MJ, Stokoe D, Gloor SL, Vigers G, Morales T, Aliagas I, Liu B, Sideris S, Hoeflich KP, Jaiswal BS, Seshagiri S, Koeppen H, Belvin M, Friedman LS, Malek S: RAF inhibitors prime wild-type RAF to activate the MAPK pathway and enhance growth. Nature 2010;464:431-435.

43 Jiang S, Wang Q, Feng M, Li J, Guan Z, An D, Dong M, Peng Y, Kuerban K, Ye L: C2-ceramide enhances sorafenib-induced caspase-dependent apoptosis via PI3K/AKT/mTOR and Erk signaling pathways in HCC cells. Appl Microbiol Biotechnol 2017;101:1535-1546.

44 Su TH, Shiau CW, Jao P, Liu CH, Liu CJ, Tai WT, Jeng YM, Yang HC, Tseng TC, Huang HP, Cheng HR, Chen PJ, Chen KF, Kao JH, Chen DS: Sorafenib and its derivative SC-1 exhibit antifibrotic effects through signal transducer and activator of transcription 3 inhibition. Proc Natl Acad Sci U S A 2015;112:7243-7248.

45 Bowman T, Garcia R, Turkson J, Jove R: STATs in oncogenesis. Oncogene 2000;19:2474-2488.

46 Toyonaga T, Nakano K, Nagano M, Zhao G, Yamaguchi K, Kuroki S, Eguchi T, Chijiiwa K, Tsuneyoshi M, Tanaka M: Blockade of constitutively activated Janus kinase/signal transducer and activator of transcription-3 pathway inhibits growth of human pancreatic cancer. Cancer Lett 2003;201:107-116.

47 Jastrzebski K, Zdzalik-Bielecka D, Maminska A, Kalaidzidis Y, Hellberg C, Miaczynska M: Multiple routes of endocytic internalization of PDGFRbeta contribute to PDGF-induced STAT3 signaling. J Cell Sci 2017;130:577-589.

48 Gruffaz M, Vasan K, Tan B, Ramos da Silva S, Gao SJ: TLR4-mediated inflammation promotes KSHV-induced cellular transformation and tumorigenesis by activating the STAT3 pathway. Cancer Res 2017;77:70947108

-49 Park J, Kim S, Joh J, Remick SC, Miller DM, Yan J, Kanaan Z, Chao JH, Krem MM, Basu SK, Hagiwara S, Kenner L, Moriggl R, Bunting KD, Tse W: MLLT11/AF1q boosts oncogenic STAT3 activity through Src-PDGFR tyrosine kinase signaling. Oncotarget 2016;7:43960-43973. 


\section{Cellular Physiology Cell Physiol Biochem 2018;47:1751-1768

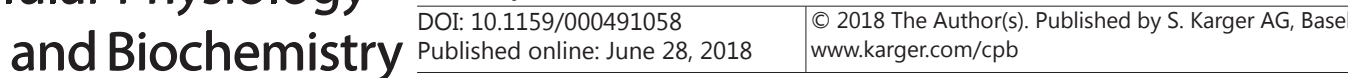

Fang et al.: Synergistic Effect of Sorafenib and Melatonin

-50 Kong J, Kong F, Gao J, Zhang Q Dong S, Gu F, Ke S, Pan B, Shen Q Sun H, Zheng L, Sun W: YC-1 enhances the anti-tumor activity of sorafenib through inhibition of signal transducer and activator of transcription 3 (STAT3) in hepatocellular carcinoma. Mol Cancer 2014;13:7.

-51 Yuan L, Collins AR, Dai J, Dubocovich ML, Hill SM: MT(1) melatonin receptor overexpression enhances the growth suppressive effect of melatonin in human breast cancer cells. Mol Cell Endocrinol 2002;192:147156.

52 Jablonska K, Pula B, Zemla A, Owczarek T, Wojnar A, Rys J, Ambicka A, Podhorska-Okolow M, Ugorski M, Dziegiel P: Expression of melatonin receptor MT1 in cells of human invasive ductal breast carcinoma. J Pineal Res 2013;54:334-345.

53 Lamont K, Nduhirabandi F, Adam T, Thomas DP, Opie LH, Lecour S: Role of melatonin, melatonin receptors and STAT3 in the cardioprotective effect of chronic and moderate consumption of red wine. Biochem Biophys Res Commun 2015;465:719-724.

54 Lau WW, Ng JK, Lee MM, Chan AS, Wong YH: Interleukin-6 autocrine signaling mediates melatonin MT(1/2) receptor-induced STAT3 Tyr(705) phosphorylation. J Pineal Res 2012;52:477-489.

55 Schwartz C, Ballinger MA, Andrews MT: Melatonin receptor signaling contributes to neuroprotection upon arousal from torpor in thirteen-lined ground squirrels. Am J Physiol Regul Integr Comp Physiol 2015;309:R1292-1300. 